\title{
Improvement of Ural-20R borer miner loading augers
}

\author{
A.E. Sukhanov ${ }^{1}$, D.I. Shishlyannikov ${ }^{1}$, D.S. Kormshchikov ${ }^{2}$ \\ ${ }^{1}$ Perm National Research Polytechnic University, Department of Mining Electromechanics, Perm, Russia \\ ${ }^{2}$ Mining Institute of the Ural Branch of the Russian Academy of Sciences, Department of Aerology and \\ Thermophysics, Perm, Russia
}

\begin{abstract}
The paper analyses haulage equipment features of the Ural-20R borer miner. The process of loading ore with an auger is accompanied by circulation and grinding. This negatively affects the efficiency of mineral processing and causes increased dust formation and the need to use energyintensive methods to reduce the concentration of dust in the bottomhole space. The authors of the work justify the rational geometric parameters of the design of the loading auger of the Ural-20R combine, which will reduce the circulation and crushing of ore during loading.
\end{abstract}

\section{INTRODUCTION}

Crawler-mounted borer miner Ural-20R is the most common continuous miner used in Russian potash mines. Its actuator is equipped with a cutter rock-breaking tool.

The Ural-20R haulage equipment consists of two augers and a scraper conveyor. The borer miner auger cuts the bottom part of the face and delivers the broken rock mass to the scraper conveyor.

The process of loading ore with a screw is accompanied by its circulation and grinding, which negatively affects the efficiency of mineral processing and causes increased dust formation and the need to use energy-intensive methods to reduce the concentration of dust in the face working space.

One of the ways to reduce the formation of dust-like refractory fractions of ore is to optimize the process of its shipment from the face working space, which is the subject of this study.

\section{TIMELINESS}

Cutting and loading materials cause ore circulation and grinding. It leads to a reduction in the size of ore pieces. Smaller pieces (less than $0.25 \mathrm{~mm}$ ) complicate the processing of minerals.. According to the scientific literature [2], the content of pulverized particles in the processed ore complicates the operation of concentration plants and entails a decrease in the profit of mining enterprises. The circulation is caused by several factors, such as ore friction on blades and the hub, ore transfer by cutter fists to the auger hub. 
The greatest over-grinding of ore occurs at the stage of rock mass destruction and transportation to the skip winding. Figure 1showsa graph of changes in the yield of refractory classes at different stages of potash ore mining. The data were obtained experimentally by sampling and conducting a sieve analysis at the BKPRU-4 mine, PAOUralkali.

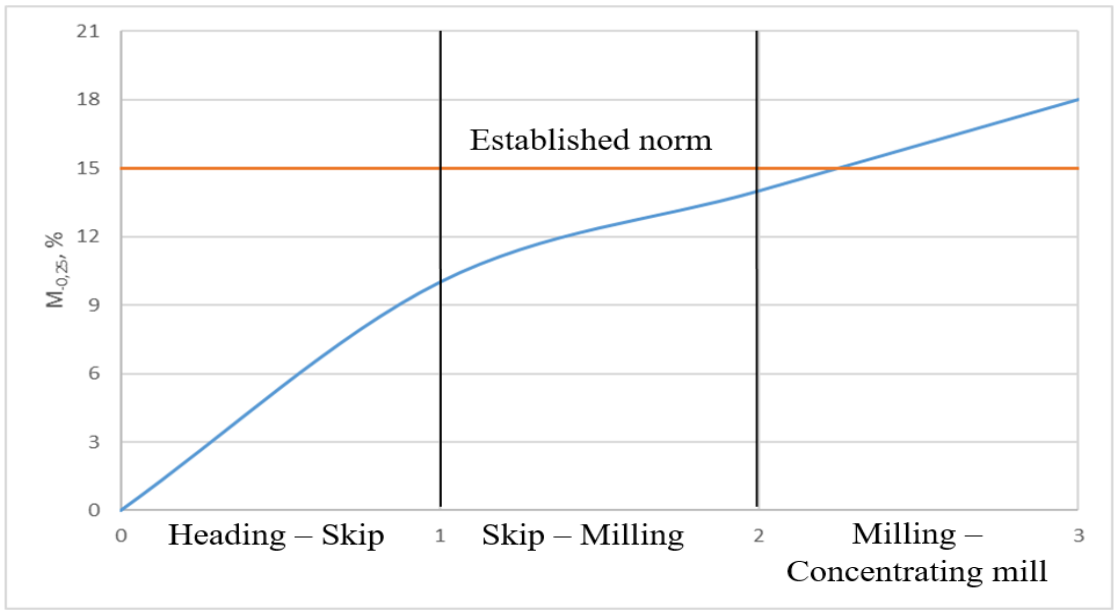

Fig. 1. Fine yield fractions at different stages of production.

The main objective is to investigate methods for improving haulage equipment efficiency. Efficiency is determined by minimum grinding of the transported rock mass at the nominal borer miner performance. One way to overcome this problem is to confirm the rational parameters of haulage equipment.

Rock mass delivery by the screw is a complex multifactorial process. This process is characterized by a significant variation in parameter values.

\section{Mathematical MOdeling OF THE SCREW PERFormanCE}

The process of mineral transport by an auger causes ore circulation that negatively affectsthescrew performance and leads to the formation of dust in the working area. $[3,4]$. The circulation is caused by friction of the ore on the blades and the hub, feeding the ore by the cutters outsidethe screw hub.

The screw performance is determined by the following formula [5]:

$$
Q_{s c}=\frac{\pi}{4}\left(D^{2}-d^{2}\right) \gamma n K_{f} K_{c}^{-1}\left(S-\frac{\delta N_{3}}{\cos \cos \alpha}\right),
$$

where $D=$ screw diameter along the blade; $d=$ auger hub diameter, $\mathrm{m} ; \alpha=$ auger blades elevation angle, deg.; $S=$ blade pitch, $\mathrm{m} ; \delta=$ blade thickness, $\mathrm{m} ; N_{3}=$ blade approaches, pcs; $n$ $=$ screw rotation frequency, $\mathrm{rpm} ; K_{f}=$ screw fill factor; $K c=$ ore circulation factor; $\gamma=$ potash ore density in the bulk.

The calculated values are taken from the borer miner technical passport: $D=0.68 \mathrm{~m} ; d=0.4$ $\mathrm{m} ; \alpha=15.8^{\circ} ; S=0.48 \mathrm{~m} ; \delta=0.035 \mathrm{~m} ; N_{3}=1 \mathrm{pc} . ; n=40.5 \mathrm{rpm} ;$ and $\gamma=1.35 \mathrm{t} / \mathrm{m} 3$.

Figure 2 shows the screw cross-section todetermine the filling degree. 


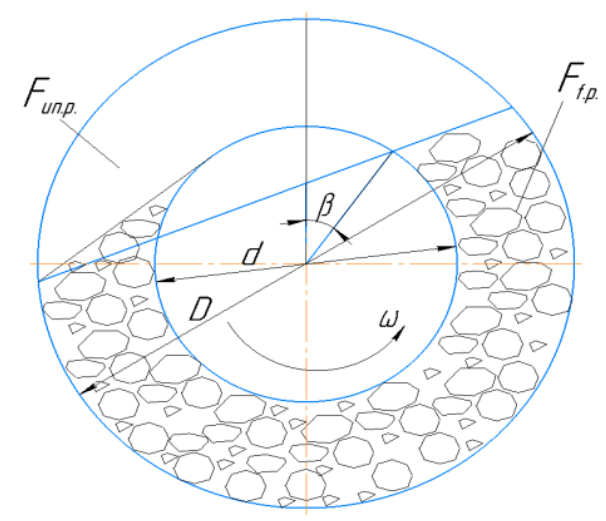

Fig. 2. The screw cross-section design scheme.

The values of this coefficient depend on moisture, strength and ore abrasiveness, adhesive properties, as well as the size of the pieces. The angle $\beta$ determines the boundary above which the ore falls on the screw surface and is transported through the hub [6]. When transporting potash ore with the Ural-20R borer miner screws, the angle $\beta$ taken according to experimental research data is equal to $35^{\circ}$ [7].

Figure 1 shows that the fill factor can be presented as:

$$
K_{f}=\frac{F_{f . p .}}{F_{u n . p .}+F_{f . p .}}
$$

where $F_{\text {f.p. }}$ isthe filled part area of the screw; and $F_{\text {un.p. }}$ isthe area of the unfilled part of the screw.

The amount of ore between the blades increases as the mass of broken rock moves from the Berm cutters to the scraper conveyor. The degree of filling of the cross-section reaches its maximum value in the area of the discharge window.

The authors obtained and presented the dependencies that describe the behavior of the fill factor functions on the hub diameter atthe taken design value productivity is constant.

The equation characterizing this is as follows:

$$
K_{f}=-31.503 d^{5}+56.111 d^{4}-36.132 d^{3}+9.572 d^{2}-0.464 d+0,5
$$

From equation (3) the authors obtained the dependence of the auger performance. This value corresponds to the minimum level of grinding of ore from the diameter of the hub (Figure 3 ). 


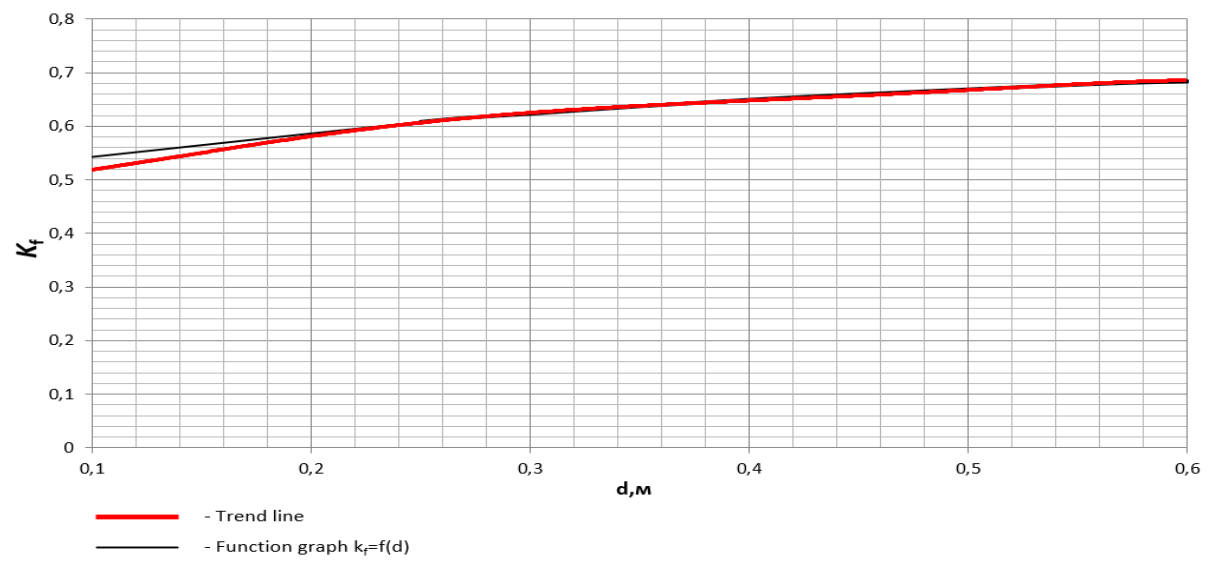

Fig. 3. Function behavior of the fill factor of the screw cross-section.

The auger performance should not limit the borer miner performance. Therefore, to calculate the rational diameter value of the hub, $\mathrm{Q} \geq 8 \mathrm{t} / \mathrm{min}$ (passport productivity value of modern modifications of the Ural-20R borer miner) is taken.

The coefficient of ore circulation in the screw $K c$ is taken equal to 1 . This value will correspond to the smallest grinding of ore.

The authors found the numerical value of the hubdiameter. This value depends on the productivity and rational screw filling factor, which corresponds to theperformances shown in Figure 4:

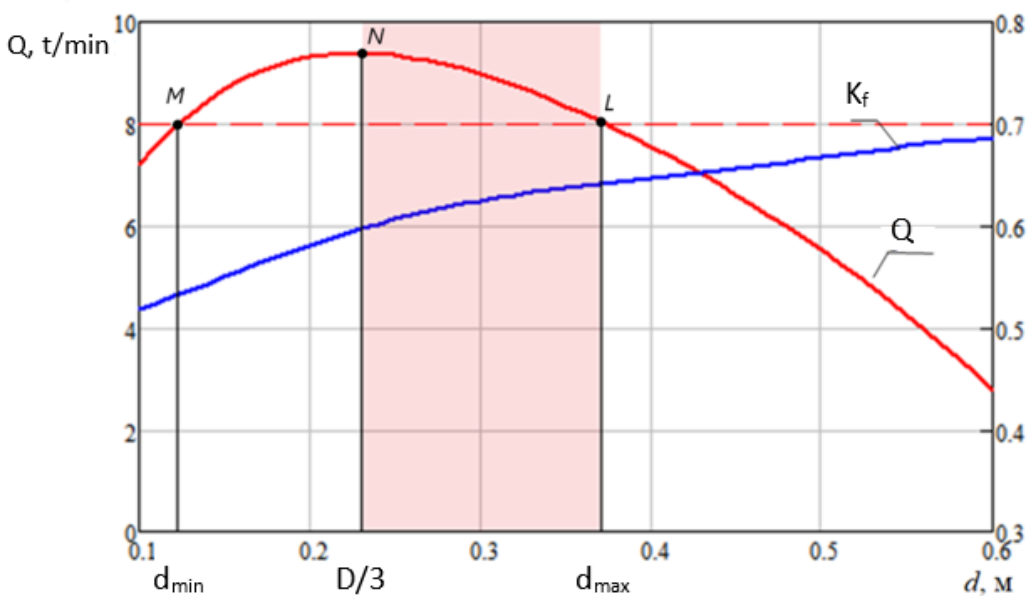

Fig. 4. Dependences of productivity and fill factor on hub diameter.

The rational hub diameter refersto the interval of values $d_{\min }-d_{\max }$. The authors suggest that the range of values from $\mathrm{d}_{\min }$ to $D / 3$ doesnot provide the necessary construction strength characteristics. The function extremum $Q=\mathrm{f}(d)$ is observed at the point $d=D / 3$. It corresponds to the highest screw performance $Q=9.41 \mathrm{t} / \mathrm{min}$.

The rational screw hub diameter is in the range of values from $D / 3$ to $d_{\max }$, which is equal to values of $0.23-0.37 \mathrm{~m}$. This construction of the modified countinuous miner Ural-20R-12 will provide the smallest degree of ore grinding during transportation. 


\section{StreamLining the AUGER Design}

The absence of closed working space in the circumferential direction and significant gaps between the auger blades, the face and the loading board negatively affect the operation of the borer miner [7]. This causes leakage of ore from the blades. As a result, a spill layer is formed on the sill. Consequently, dust is generatedin the working area.

The authors propose replacing the shield installed behind the screw loading member with a clearing share (Figure 5).

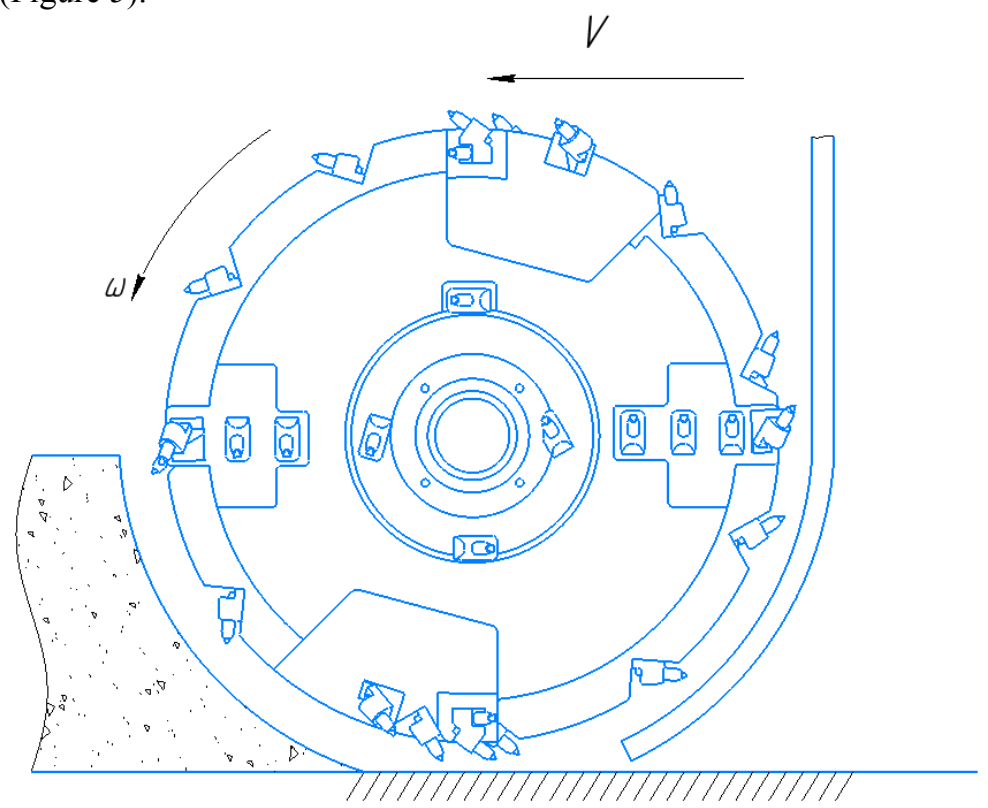

Fig. 5. An auger with a clearing share.

It is necessary to change the position of the fists with incisors. Fists should be located on the non-working side of the blade and not protrude beyond its diameter (Figure 6.7).

Fig. 6. An auger with recessed tool holders in the blades.

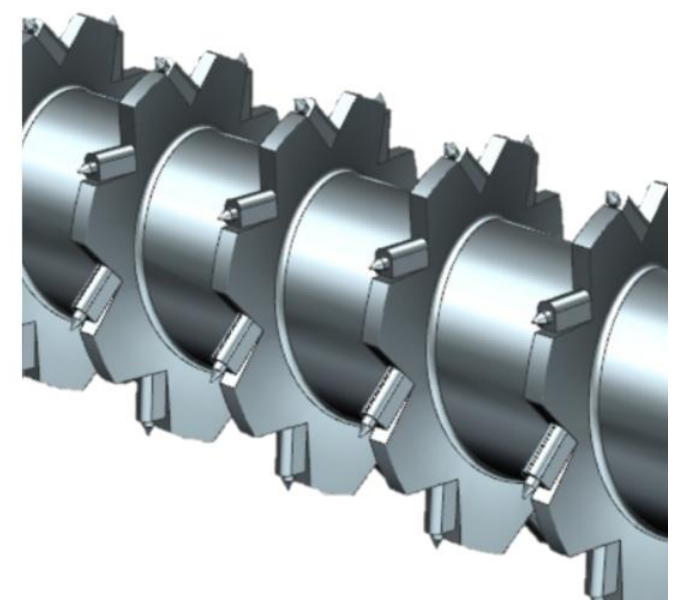




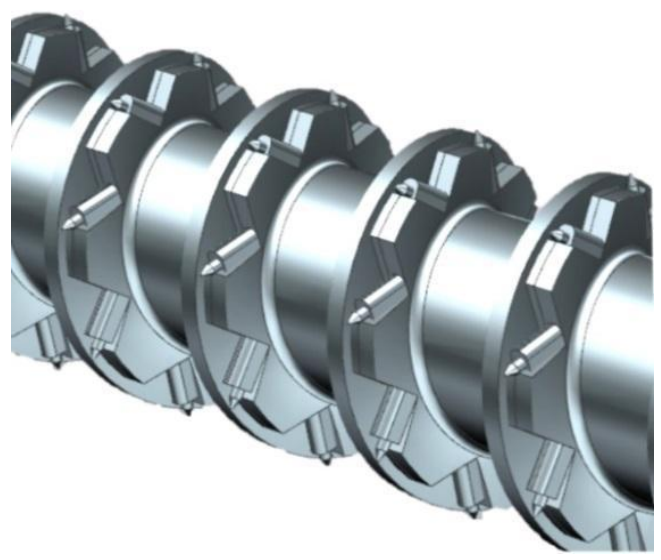

Fig 7. An auger with tool holders integrated into the blades.

This layout requires the installation of the other cutters with a longer reach, such as the RS$14 \mathrm{U}$ type.

\section{Conclusion}

All things considered, the auger hub diameter range from $0.23 \mathrm{~m}$ to 0.37 is the most favorable. These parameters will ensure minimal ore grinding. The proposed design solutions will also help to increase the efficiency of Ural-20R borer miner.

\section{REFERENCES}

1. Ural-20R heading-and-winning machine: operation and maintenance manual for Kopeisk Machine-Building Plant OJSC, part 1, (2013).

2. R.Kh. Teterina, L.Ya. Sabirov, L.N. KirichenkoThe technology of flotation concentration of potash ores. (Perm: Solikamsk Printing House, 2002).

3. N.V. Chekmasov, V.V. Gabov, D.I. Shishlyannikov, L.A. Loskutov Improving the efficiency of the destruction process of the potash array by cutters of the borer miner activator members, News of Higher Education Institutions. Mountain Journal, 5, 43-49 2015.

4. N.V. Chekmasov, D.I. Shishlyannikov, V.M. Demin Improving the efficiency of the loading potash ores process during the work of heading-and-winning machines, News of Higher Educational Institutions. Mountain Journal, 6, 4-8 (2016).

5. V.I. Solod, V.N. Getopanov, V.M. RachekDesign and construction of mining machines and complexes. (Moscow: Nedra, 1982).

6. A.V. Dokukin, A.G. Frolov, E.Z. PozinChoice of parameters of winning machines. Scientific and methodological foundations. (Moscow: Science, 1976).

7. V.N. Werner Research and substantiation of rational parameters of screw loading and transporting members of winning machines (1999). 